\title{
Micro/Nanostructure and Tribological Characteristics of Pressureless Sintered Carbon Nanotubes Reinforced Aluminium Matrix Composites
}

\author{
P. Manikandan, ${ }^{1}$ R. Sieh, ${ }^{2}$ A. Elayaperumal, ${ }^{1}$ H. R. Le, ${ }^{3}$ and S. Basu ${ }^{2}$ \\ ${ }^{1}$ Department of Mechanical Engineering, Anna University, Chennai 600 025, India \\ ${ }^{2}$ School of Marine Science and Engineering, Plymouth University, Plymouth PL4 8AA, UK \\ ${ }^{3}$ Department of Engineering, University of Derby, Derby DE22 3AW, UK \\ Correspondence should be addressed to H. R. Le; h.le@derby.ac.uk
}

Received 19 November 2015; Accepted 19 January 2016

Academic Editor: Roham Rafiee

Copyright (C) 2016 P. Manikandan et al. This is an open access article distributed under the Creative Commons Attribution License, which permits unrestricted use, distribution, and reproduction in any medium, provided the original work is properly cited.

\begin{abstract}
This study reports the manufacture, microstructure, and tribological behaviour of carbon nanotube reinforced aluminium composites against pure aluminium. The specimens were fabricated using powder metallurgy method. The nanotubes in weight percentages of $0.5,1.0,1.5$, and 2.0 were homogeneously dispersed and mechanically alloyed using a high energy ball milling. The milled powders were cold compacted and then isothermally sintered in air. The density of all samples was measured using Archimedes method and all had a relative density between $92.22 \%$ and $97.74 \%$. Vickers hardness increased with increasing CNT fraction up to $1.5 \mathrm{wt} \%$ and then reduced. The microstructures and surfaces were investigated using high resolution scanning electron microscope (SEM). The tribological tests showed that the CNT reinforced composites displayed lower wear rate and friction coefficient compared to the pure aluminium under mild wear conditions. However, for severe wear conditions, the CNT reinforced composites exhibited higher friction coefficient and wear rate compared to the pure aluminium. It was also found that the friction and wear behaviour of CNT reinforced composites is significantly dependent on the applied load and there is a critical load beyond which CNTs could have adverse impact on the wear resistance of aluminium.
\end{abstract}

\section{Introduction}

Metal matrix composites (MMCs) reinforced with nanoparticles and nanotubes are finding increasing use in fields such as aerospace, architectural structure, renewable energy, alternative transport, and electronics in order to make lighter and stronger structures [1-3]. Among various MMCs, aluminium (Al) has attracted significant interest because of its excellent strength, low density, and corrosion resistance. Aluminium and its alloys are important lightweight materials with low density, high thermal conductivity, good mechanical properties, and corrosion resistance. The combination of unique properties of carbon nanotubes (CNTs) and aluminium alloys has, therefore, great potential in many weight sensitive applications $[4,5]$. Since poor tribological performance limits its use in wear related applications, many efforts have been made to improve their wear and mechanical resistance $[4,6]$. Recent research has been extended to evaluate the effect of nanoparticles on the wear resistance of aluminium nanocomposites. There has been significant interest in carbon materials because of their special electrical, optical, and mechanical properties [7]. In particular, CNTs have attracted scientific and technological interest due to their unique chemical and physical properties. CNTs have also been proposed as a reinforcement material due to its high modulus of elasticity, high tensile strength, and large bending angles after being discovered by Iijima [8]. In particular, if the CNTs composite is made with aluminium matrix, it can inherit the lightweight property of aluminium [9]. To use CNTs for technical applications, the mechanical properties and characteristics of tribology need to be investigated through determination of the wettability between materials, the CNTs content, the homogeneous dispersion conditions, and the proper manufacturing method 
[10, 11]. Several methods have been proposed and implemented to synthesize nanocrystalline matrix reinforced with multiwalled carbon nanotubes (MWCNTs), such as thermal spraying [12, 13], sintering [14-16], mechanical alloying (MA) [17-22], semisolid powder processing [23, 24], spark plasma sintering (SPS) $[25,26]$, friction stir processing $[27,28]$, flake powder metallurgy [29], spark plasma extrusion [30], and nanoscale dispersion [31]. However, the use of MWCNTs as reinforcement in aluminium MMCs is a great challenge due to their agglomeration and poor dispersion of the nanotubes. Among the aforementioned methods, SPS appears to be best for mechanical properties but requires expensive equipment. Pressureless sintering process is more economical and has the potential to produce large components. MA is employed prior to sintering or SPS to improve the dispersion of nanoparticles within metal matrices [32]. Improvement in wear resistance of aluminium with the addition of CNTs was reported in previous studies $[4,32,33]$. Al-Qutub et al. [4] clarified that the friction and wear behaviour of Al-CNTs composites is largely dependent on the applied load. There exists a critical load beyond which CNTs could have adverse impact on the wear resistance of aluminium alloys. Choi and coworkers [32] investigated the mechanical properties and wear mechanisms of aluminium nanocomposites. They found that aluminium infiltrated MWCNTs formed a strong interface with the aluminium matrix by mechanical interlocking. The strength and wear resistance were significantly improved due to the decrease of grain size and the addition of CNTs. The coefficient of friction was also reduced. The optimum CNTs content for minimum wear loss was reported to be $4.5 \mathrm{vol} \%$. They also reported that the coefficient of friction and the wear rate increased with increasing load but decreased with increasing sliding speed. Zhou and coworkers [33] developed aluminium composites with CNTs via pressureless infiltration of aluminium into CNT-Mg-Al composite preformed in $\mathrm{N}_{2}$ atmosphere at $800^{\circ} \mathrm{C}$. They found that CNTs were well dispersed and embedded in the $\mathrm{Al}$ matrix and the friction coefficient and wear rate of the composite decreased with increasing volume fraction of CNTs content. It can therefore be summarised that the tribological properties of Al-CNTs composites are highly dependent on the method used for dispersing CNTs, the CNTs content, and the fabrication method used to consolidate the composite. Mechanical alloying (MA), also known as ball milling, is a process which has been highly developed and widely applied to preparing a wide range of alloys, intermetallic compounds, and composites in the amorphous or nanocrystalline form. Some alloys with homogenous microstructure can be readily obtained by MA from components having significant difference in specific weight and melting point or being even virtually immiscible [34]. MA is a powder metallurgy processing technique that involves repeated cold welding, fracturing, and rewelding of particles using a high energy ball mill [35]. It can be used to achieve a uniform distribution of the reinforcement in metal matrix nanocomposites (MMNCs) with reduced agglomeration. It was found that dispersion of CNTs in MMNCs through MA is related to several processing variables including pretreatment of CNTs, type of milling, ball-to-powder weight ratio, milling speed, milling time,
TABLE 1: Chemical composition of aluminium powder.

\begin{tabular}{lcccccccc}
\hline Element & $\mathrm{Si}$ & $\mathrm{Cu}$ & $\mathrm{N}$ & $\mathrm{HCl}$ & $\mathrm{Fe}$ & $\mathrm{Mn}$ & $\mathrm{Ti}$ & $\mathrm{Al}$ \\
\hline Amount (\%) & 0.1 & 0.02 & 0.001 & 0.005 & 0.1 & 0.02 & 0.03 & Balance
\end{tabular}

and process control agent [36]. Bakshi and coworkers [37] reviewed that most of the corrosion studies are performed on electrodeposited Ni-CNT composite coatings and ZnCNT composite coating. They reported that electrodeposited coatings are more prone to corrosion due to the presence of pores and voids. These studies indicate that the addition of CNTs may improve the corrosion resistance due to two reasons. Firstly, the chemical inertness of the CNTs helps forming a passive layer on the coating surface. Secondly, CNTs help filling up the voids and pores of electrodeposited coatings reducing initiation of localised corrosion. The aim of the present study is to compare the hardness, density, microstructure, and sliding wear properties of Al-based composites fabricated by MA using a high energy ball mill. These composites were reinforced with various CNTs contents (0.5$2 \mathrm{wt} \%$ ) based on previous works. Test samples were obtained by cold compaction and sintering from ball milled powders. Vickers hardness and density are obtained by established methods. Wear behaviour of the specimens was tested against steel discs using various loads in $300 \mathrm{~m}$ of sliding distance. Unless otherwise specified, CNTs in this work are referred to as MWCNTs.

\section{Experimental Procedure}

2.1. Materials. The matrix material used for the composite fabrication was pure $\mathrm{Al}$ (99.7\%) powder with near spherical particle average sizes of $78 \mu \mathrm{m}$ obtained from Loba Chemie in Mumbai, India. MWCNTs with a nominal diameter of 20$30 \mathrm{~nm}$ in lengths of $3-8 \mu \mathrm{m}$ were used as reinforcement to the matrix. These were obtained from Intelligent Materials Private Ltd., a supplier in Punjab, India, for Nanoshel, a company based in the United States. Ethanol was used as a medium in the ball milling of $\mathrm{CNT}$ and $\mathrm{Al}$ powders. The chemical composition of Al powder is presented in Table 1.

2.2. Fabrication of Nanocomposite Material. Elemental powders were used to fabricate the aluminium. CNTs with a diameter in the range of $20-30 \mathrm{~nm}$ and length of $1-10 \mu \mathrm{m}$ were added in $0.5,1.0,1.5$, and $2.0 \mathrm{wt} \%$. The CNTs were dispersed into the aluminium powder by ball milling for 2 hours. The ball-to-powder weight ratio was $10: 1$. The milled powders were cold pressed in steel mould at $650 \mathrm{MPa}$ to form $8 \mathrm{~mm}$ diameter cylindrical pins of $50 \mathrm{~mm}$ height. Consolidated samples were pressurelessly sintered for 2 hours at $723 \mathrm{~K}$ with a heating and a cooling rate of $100 \mathrm{~K} / \mathrm{min}$. For the purpose of comparison monolithic aluminium was also prepared by the same process.

2.3. Pin-on-Disc Tests for Sliding Wear. A schematic representation of the sliding wear test machine is presented in Figure 1. The components were designed to get a pin-on-disc 


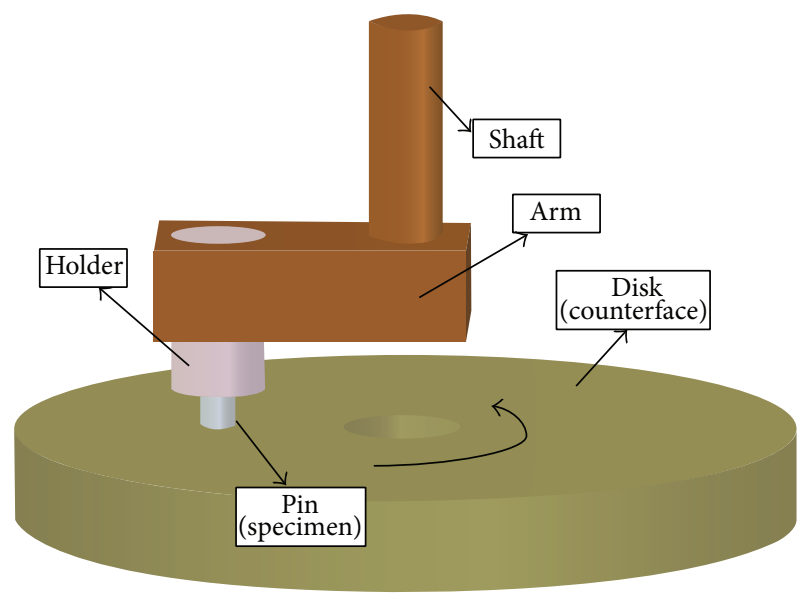

Figure 1: Pin-on-disc tribometer [3].

configuration with a holder positioned perpendicularly to the rotating disc. Specimens underwent the sliding wear tests against EN31 steel disc. Loads of $0.1 \mathrm{~kg}, 0.2 \mathrm{~kg}, 0.3 \mathrm{~kg}, 0.4 \mathrm{~kg}$, and $0.5 \mathrm{~kg}$ were applied directly to the specimens with the use of the pin as indicated in Figure 1. The flat surface of the pin polished with $9 \mu \mathrm{m}$ polishing pad. An EN31 steel disc with a hardness of $59 \mathrm{HRC}$ was used as counterface. An average roughness $R_{a}$ value of $0.3 \mu \mathrm{m}$ was achieved for the disc through grinding using alumina abrasive wheel. The surfaces of the pin and disc were cleaned with acetone prior to the tests. The tests were carried out under dry sliding conditions at constant sliding speed of $0.5 \mathrm{~m} / \mathrm{s}$ and normal loads in the range of 0.1 to $0.5 \mathrm{~kg}$. The sliding distance was kept constant at $300 \mathrm{~m}$. Wear rate values were obtained by taking the average from three repeated tests. The friction coefficient was continuously recorded using $x$ - $y$ plotter interfaced to the tribometer. A scanning electron microscope (SEM) was used to inspect the worn surfaces of the specimens.

\section{Results and Discussion}

3.1. Densification and Micro/Nanostructure. Pressureless sintering takes longer than spark plasma sintering reported previously by Silvestre [2]. There was an oxidised layer on the surface of the samples which is loose and brittle. Nevertheless, the material inside is a dense material. The density of all samples was measured by Archimede's method and all had a relative density between $92.22 \%$ and $97.74 \%$.

High resolution SEM image of pure aluminium sintered for $2 \mathrm{~h}$ at $723 \mathrm{~K}$ showed a uniform and homogenous microstructure of the alloy as shown in a typical SEM micrograph in Figure 2(a). Similarly $0.5 \mathrm{wt} \%, 1.0 \mathrm{wt} \%$, and $2.0 \mathrm{wt} \%$ composites sintered for $2 \mathrm{~h}$ at $723 \mathrm{~K}$ also exhibit a dense microstructure as shown in Figures 2(b)-2(d). With increasing content of CNTs, the microstructure is less uniform and there are more nanoporous areas observed. It is believed that these are the undispersed CNTs clusters showing the cross section of the hollow nanotubes. This is correlated with the slight reduction in relative density reported above.
TABLE 2: Effect of CNT content on density and hardness properties.

\begin{tabular}{lcccc}
\hline $\begin{array}{l}\text { CNT } \\
\text { wt.\% }\end{array}$ & $\begin{array}{c}\text { Theoretical } \\
\text { density }\left(\mathrm{g} / \mathrm{cm}^{3}\right)\end{array}$ & $\begin{array}{c}\text { Measured } \\
\text { density }\left(\mathrm{g} / \mathrm{cm}^{3}\right)\end{array}$ & $\begin{array}{c}\text { Hardness } \\
(\mathrm{HV})\end{array}$ & $\begin{array}{c}\text { Relative } \\
\text { density }(\%)\end{array}$ \\
\hline 0.0 & 2.70 & 2.639 & 19.66 & 97.74 \\
0.5 & 2.697 & 2.584 & 25.60 & 95.81 \\
1.0 & 2.694 & 2.598 & 27.45 & 96.44 \\
1.5 & 2.691 & 2.570 & 30.60 & 95.50 \\
2.0 & 2.688 & 2.479 & 23.05 & 92.22 \\
\hline
\end{tabular}

3.2. Hardness. Vickers hardness was measured for pure aluminium and 0.5-2.0 wt\% CNT composites as shown in Table 2. Each data point was an average of 3 measurements for the same material.

Figure 3 shows the hardness of the composites and monolithic aluminium processed by the same procedure. The hardness of the nanocomposites increased by about $50 \%$ with CNT fraction up to $1.5 \mathrm{wt} \%$ and then decreased significantly. The increase in hardness is mainly due to the strengthening effect of CNTs. The decrease in hardness when CNT fraction is over $1.5 \%$ is coincident with the significant increase in porosity. Simões et al. [38] also found that the hardness of composite is higher than the monolithic aluminium if the CNTs are well dispersed. The hardness of composite may decrease if the CNTs are damaged during the dispersion process.

3.3. Wear Rate. A widely used equation to compute the wear rate is Archard's equation:

$$
V_{i}=K_{i} \times F \times S
$$

where $F$ is normal load $(\mathrm{kg}), S$ is sliding distance $(\mathrm{m})$, $V_{i}$ is wear volume $\left(\mathrm{mm}^{3}\right)$, and $K_{i}$ is specific wear rate coefficient $\left(\mathrm{mm}^{3} / \mathrm{kgm}\right)$. The wear rate for the monolithic Al and the composite containing $0.5 \mathrm{wt} \%, 1.0 \mathrm{wt} \%, 1.5 \mathrm{wt} \%$, and $2.0 \mathrm{wt} \%$ CNTs versus the applied load is shown in Figure 4. The experiments were carried in triplicate. The wear rate increased monotonically with the applied load. At lower loads of $0.1-0.2 \mathrm{Kg}$, the composite showed better wear resistance than pure $\mathrm{Al}$. However, at higher loads of $0.3-0.5 \mathrm{Kg}$, the wear resistance of monolithic Al was better than the composite. The wear rate of the composite increased significantly as the normal load is increased from 0.2 to $0.3 \mathrm{Kg}$ which indicates sharp change in wear mechanism from mild to severe wear regime. These results show that addition of $0.5 \mathrm{wt} \%, 1.0 \mathrm{wt} \%$, $1.5 \mathrm{wt} \%$, and $2.0 \mathrm{wt} \% \mathrm{CNTs}$ improves wear resistance of the $\mathrm{Al}$ at lower loads (mild conditions) only. At higher loads pores present in the composite and CNTs agglomerates (as shown in Figure 5) act as a source of crack initiation and cause severe subsurface fragmentation resulting in poor wear resistance of the composite compared to the monolithic aluminium. Compared to SPS processed composites reported by Silvestre [2], the sintered composites appear to be more brittle and prone to subsurface fracture. This is owing to the oxidation during the long sintering process. Moreover, weak bonding between CNTs and aluminium particles could be another 


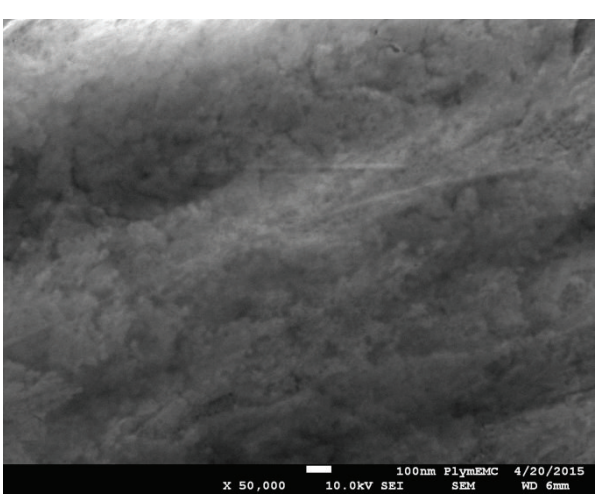

(a)

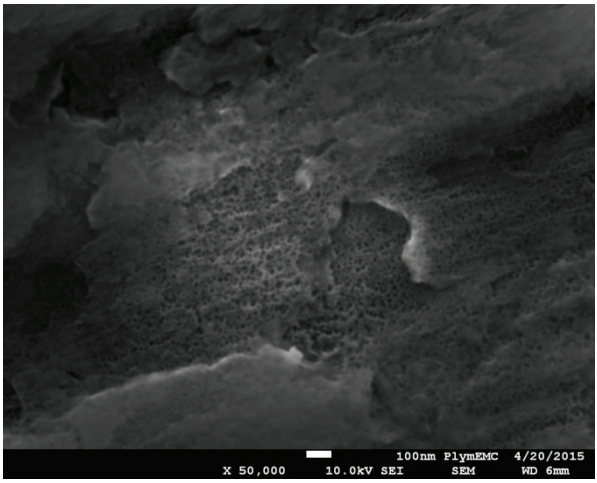

(c)

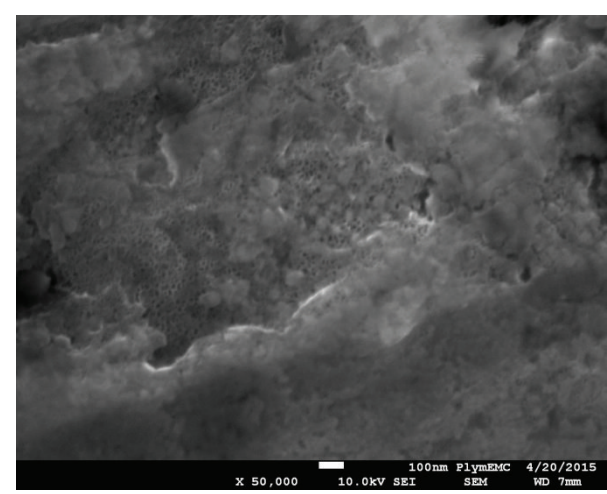

(b)

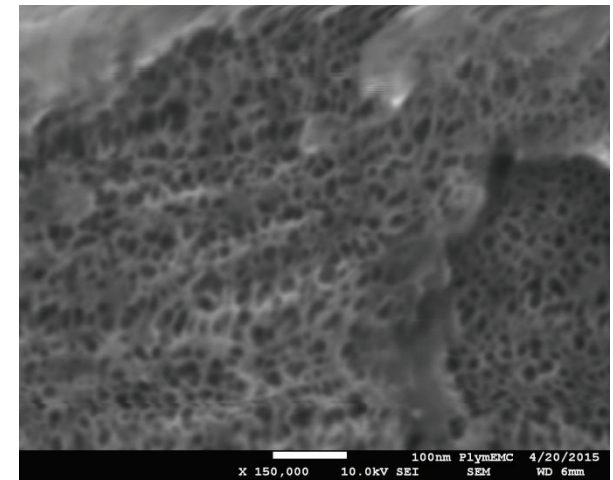

(d)

FIGURE 2: SEM micrograph of polished surface of (a) pure Al, (b) $\mathrm{Al}+0.5 \mathrm{wt} \% \mathrm{CNT}$, (c) $\mathrm{Al}+1 \mathrm{wt} \% \mathrm{CNT}$, and (d) $\mathrm{Al}+2.0 \mathrm{wt} \% \mathrm{CNT}$.

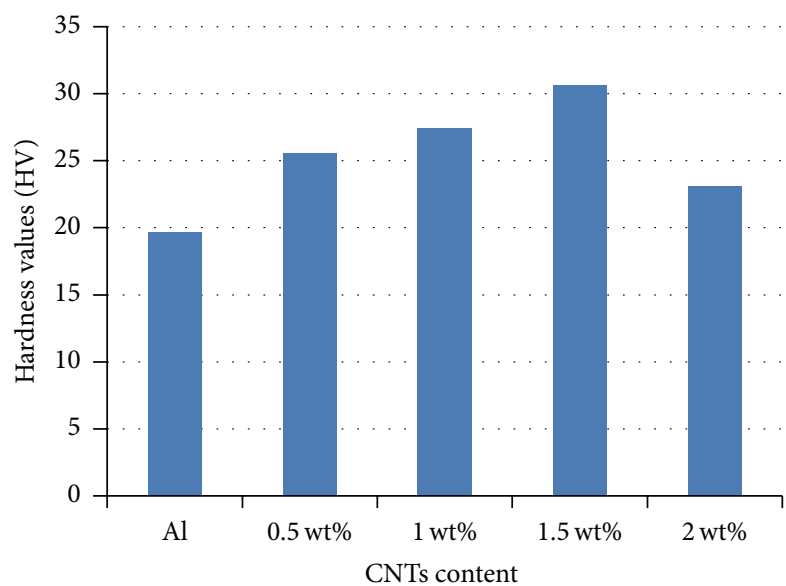

Figure 3: Hardness for the Al, $0.5 \mathrm{wt} \%$ to $2 \mathrm{wt} \% \mathrm{CNT}$.

possible reason for its severe subsurface fracturing at higher loads.

3.4. Friction Coefficient. The coefficients of friction versus the applied load for the pure aluminium and the $0.5 \mathrm{wt} \%, 1.0 \mathrm{wt} \%$, $1.5 \mathrm{wt} \%$, and $2.0 \mathrm{wt} \%$ composites are presented in Figure 6 . At a load of $0.1 \mathrm{Kg}$, for the first $250 \mathrm{~m}$ of sliding distance, the friction coefficient of the monolithic $\mathrm{Al}$ increased continuously to about 0.62 . Beyond $250 \mathrm{~m}$, it decreased slightly to about 0.6

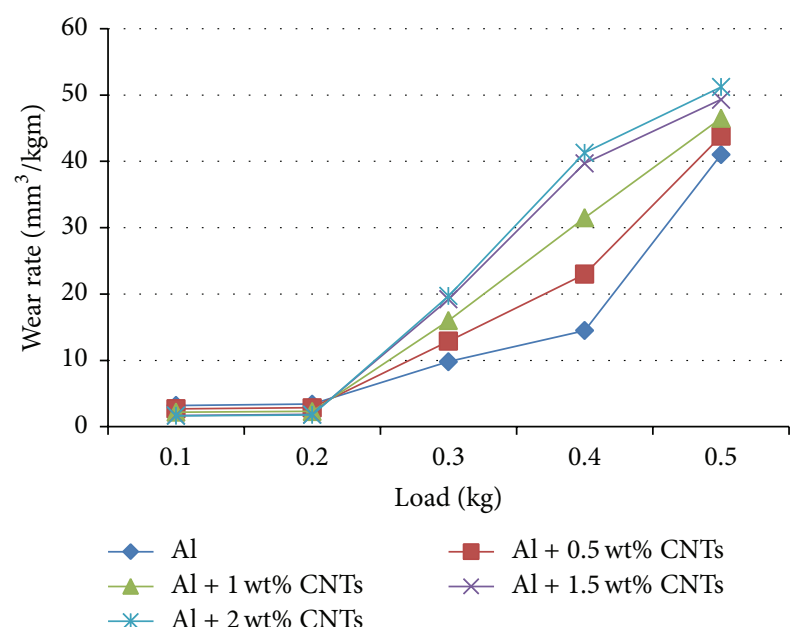

FIgURE 4: Wear rate for the $\mathrm{Al}$ and composites with $0.5 \mathrm{wt} \%$ to $2 \mathrm{wt} \%$ CNT.

for the next $100 \mathrm{~m}$. While for the $0.5 \mathrm{wt} \% \mathrm{CNT}$ composite, the friction coefficient showed considerable increase in the first $150 \mathrm{~m}$ of sliding. It then stayed in the range of $0.4-$ 0.45. It is evident that the friction coefficient of composite is not only lower but also less fluctuating compared to the monolithic alloy. Similarly for the $1 \mathrm{wt} \%, 1.5 \mathrm{wt} \%$, and $2.0 \mathrm{wt} \%$ CNT composite, the friction coefficient increased in the first 


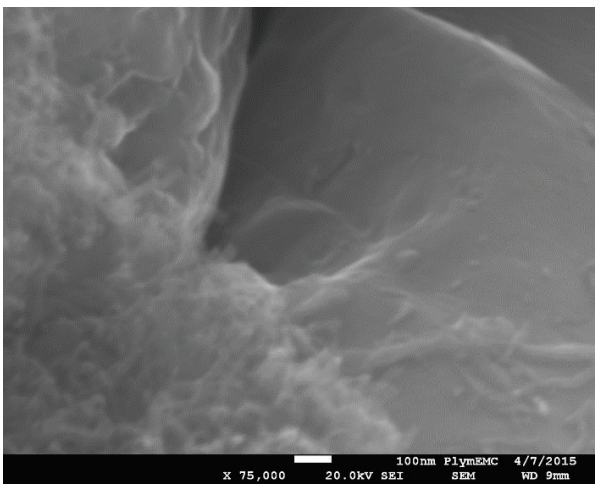

(a)

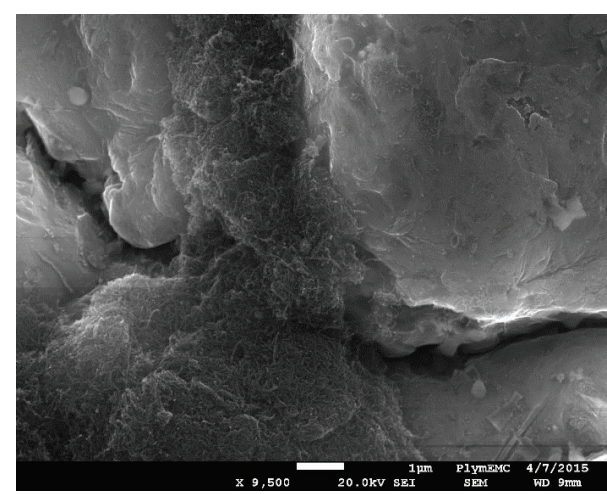

(b)

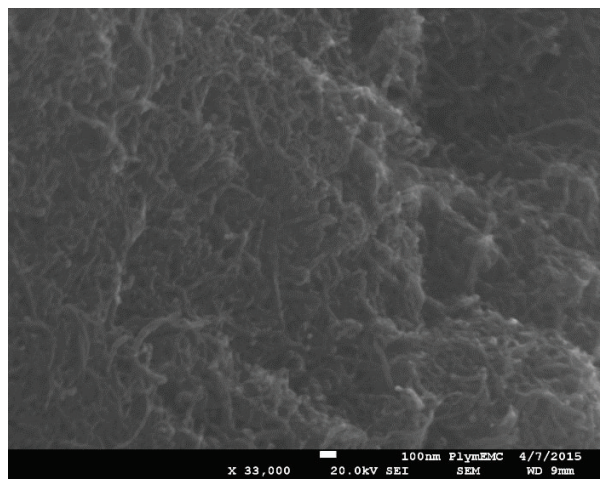

(c)

Figure 5: SEM micrograph of fractal surface of (a) $\mathrm{Al}+1 \mathrm{wt} \% \mathrm{CNT}$, (b) $\mathrm{Al}+1.5 \mathrm{wt} \% \mathrm{CNT}$, and (c) $\mathrm{Al}+2 \mathrm{wt} \% \mathrm{CNT}$.

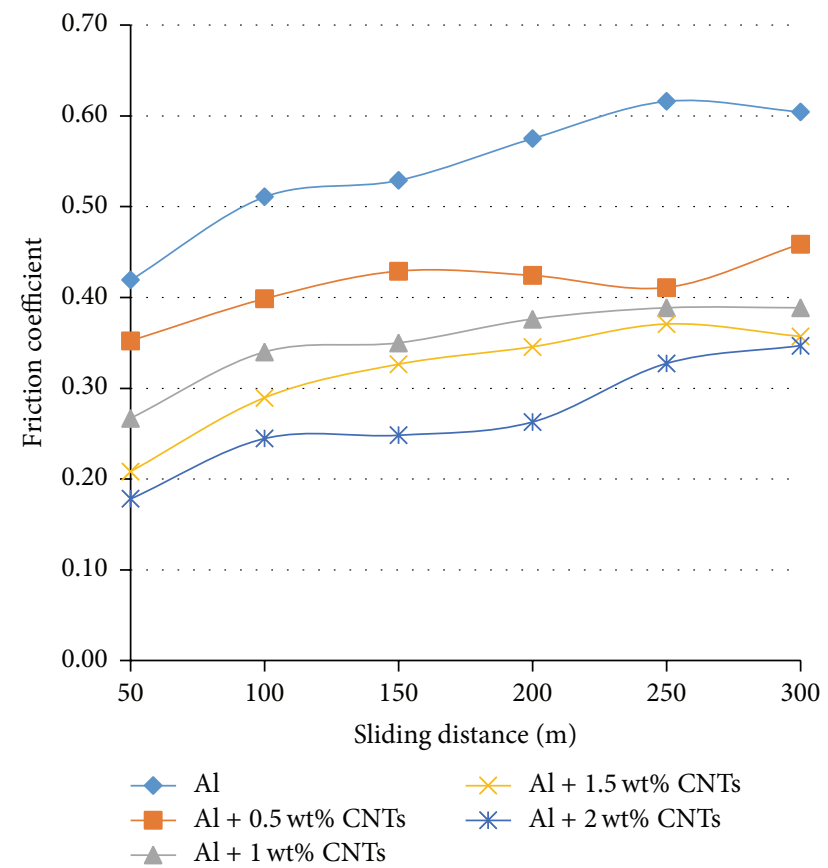

FIgURE 6: Friction coefficient for $\mathrm{Al}$ and $0.5 \mathrm{wt} \%$ to $2 \mathrm{wt} \% \mathrm{CNT}$ at $0.1 \mathrm{~kg}$.
$200 \mathrm{~m}$ of sliding. Then it remained steady at an average value of $0.4,0.35$, and 0.3 , respectively, for the remaining $100 \mathrm{~m}$. This reduction in friction may be attributed to the lubricating effect of CNTs.

The coefficient of friction versus load for the monolithic alloy and the $0.5 \mathrm{wt} \%$ to $2.0 \mathrm{wt} \%$ composites are presented in Figure 7 for a load of $0.2 \mathrm{Kg}$. It can be seen that the friction coefficient of both monolithic aluminium and composites decreased considerably compared to that obtained at a load of $0.1 \mathrm{Kg}$. For the monolithic alloy and the composites with CNTs up to $1 \mathrm{wt} \%$, the friction coefficient increased by about $20 \%$ in the first $150 \mathrm{~m}$ and then stabilises. For composites with CNTs $1.5 \mathrm{wt} \%$, the friction coefficient stayed at about 0.18 to 0.2 . For CNTs above $2 \mathrm{wt} \%$, the friction coefficient dropped by $20 \%$ to about 0.15 after $100 \mathrm{~m}$.

The coefficients of friction versus normal load for the pure aluminium and the $0.5 \mathrm{wt} \%$ to $2.0 \mathrm{wt} \%$ composites are presented in Figure 8 at a load of $0.3 \mathrm{~kg}$. It can be seen that the trend of friction is very similar to that seen at $0.2 \mathrm{~kg}$ except the $2 \mathrm{wt} \%$ composite. The monolithic aluminium and composite materials with CNTs up to $1.5 \mathrm{wt} \%$ displayed slight increase in friction coefficient with sliding distance up to $150 \mathrm{~m}$ and then levels off. The composite with $2.0 \mathrm{wt} \% \mathrm{CNTs}$ increased steadily from 0.15 to 0.22 . 


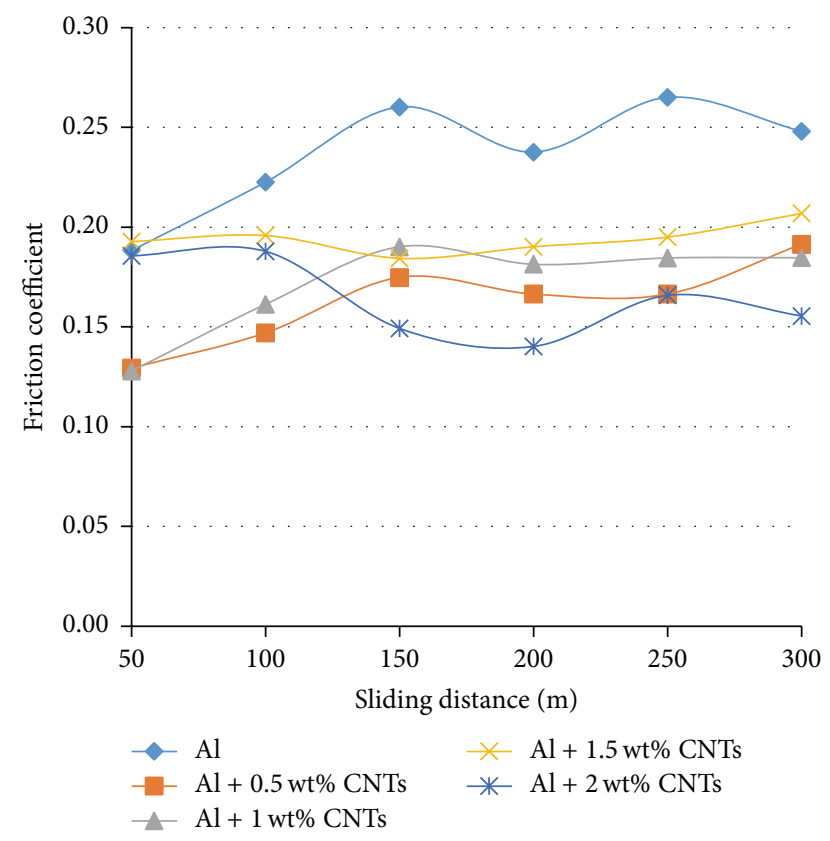

Figure 7: Friction coefficient for $\mathrm{Al}$ and $0.5 \mathrm{wt} \%$ to $2 \mathrm{wt} \% \mathrm{CNT}$ at $0.2 \mathrm{~kg}$.

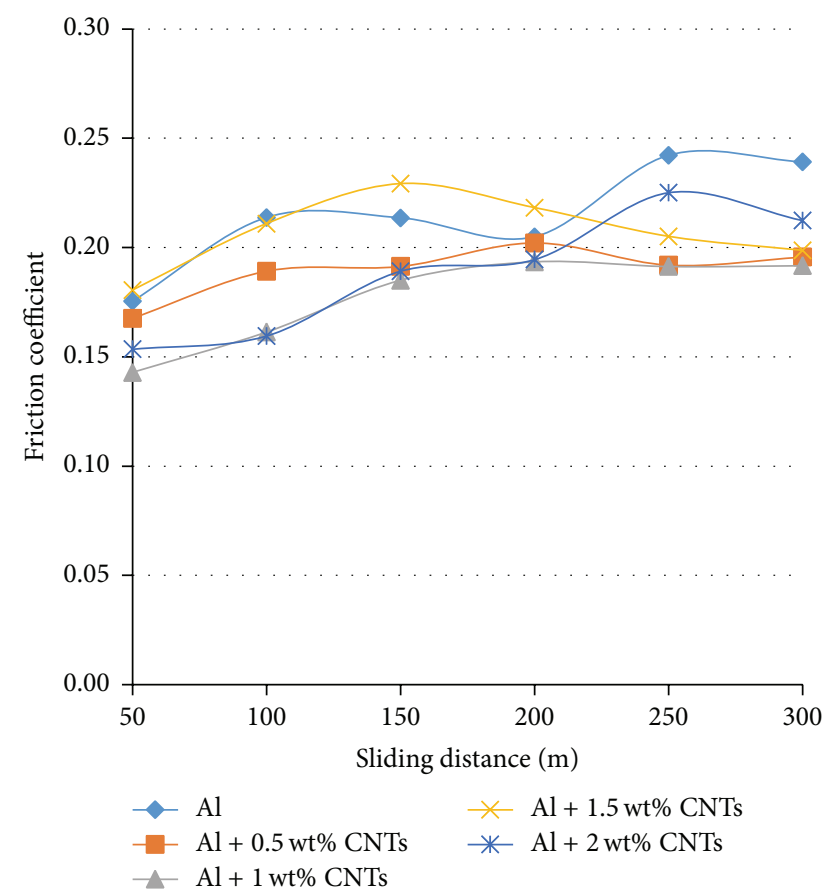

FIgURE 8: Friction coefficient for $\mathrm{Al}$ and $0.5 \mathrm{wt} \%$ to $2.0 \mathrm{wt} \% \mathrm{CNT}$ at $0.3 \mathrm{~kg}$.

The coefficients of friction for the applied load of $0.4 \mathrm{~kg}$ are presented in Figure 9. It can be seen that the variation of friction coefficient with sliding distance is smaller than that at lower applied load presented above. The friction coefficients of the monolithic alloy and the $0.5 \mathrm{wt} \%, 1.0 \mathrm{wt} \%$, $1.5 \mathrm{wt} \%$, and $2.0 \mathrm{wt} \% \mathrm{CNT}$ composites remained almost

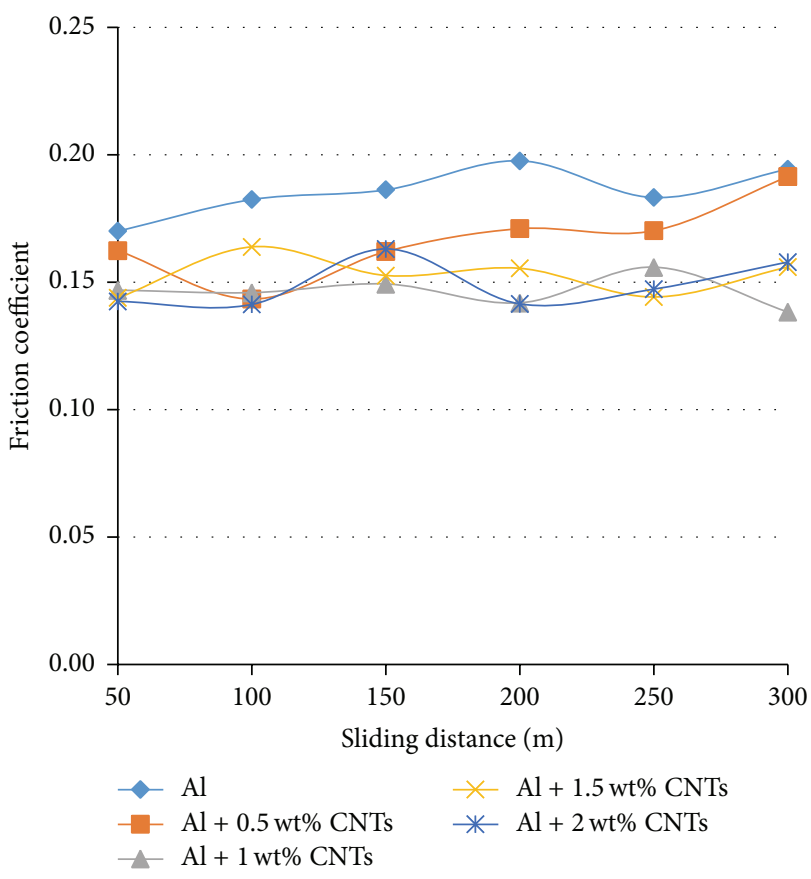

FIGURE 9: Friction coefficient for $\mathrm{Al}$ and $0.5 \mathrm{wt} \%$ to $2.0 \mathrm{wt} \% \mathrm{CNT}$ at $0.4 \mathrm{~kg}$.

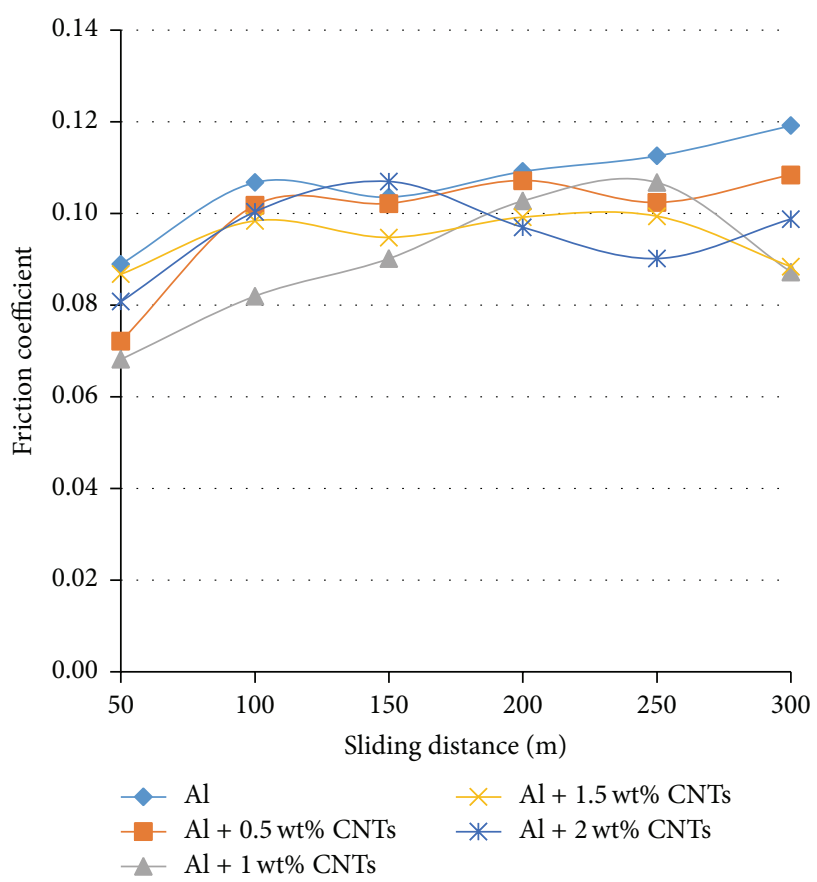

Figure 10: Friction coefficient for $\mathrm{Al}$ and $0.5 \mathrm{wt} \%$ to $2.0 \mathrm{wt} \% \mathrm{CNT}$ at $0.5 \mathrm{~kg}$.

constant at average values of $0.185,0.175,0.152,0.155$, and 0.16 , respectively.

The coefficients of friction for a load of $0.5 \mathrm{~kg}$ are presented in Figure 10. It can be seen that both aluminium and composite materials exhibited considerable variation in friction coefficient for the first $100 \mathrm{~m}$ of sliding,but for 


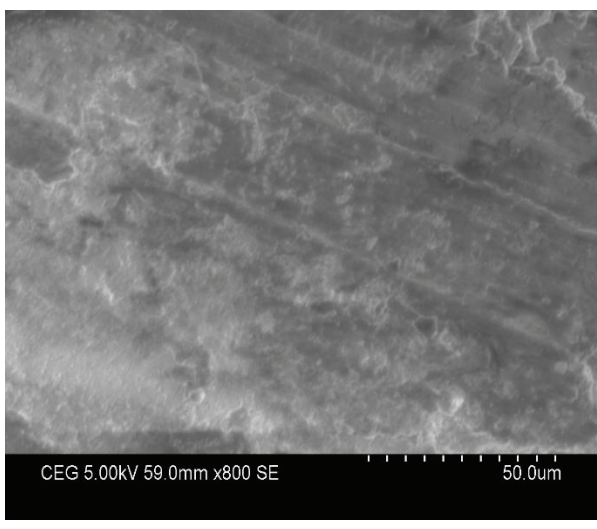

(a)

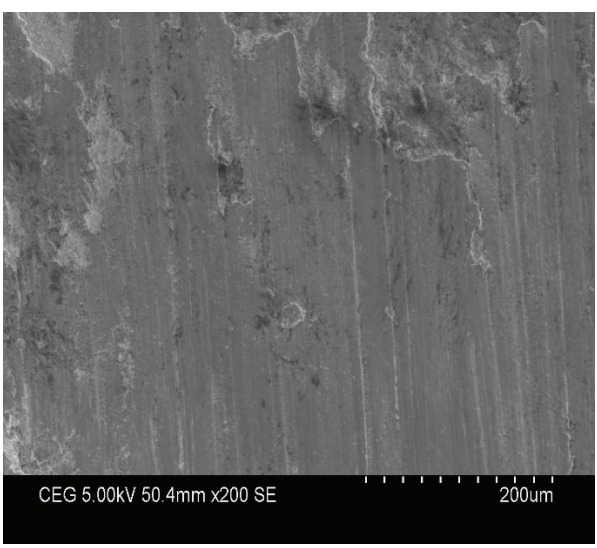

(c)

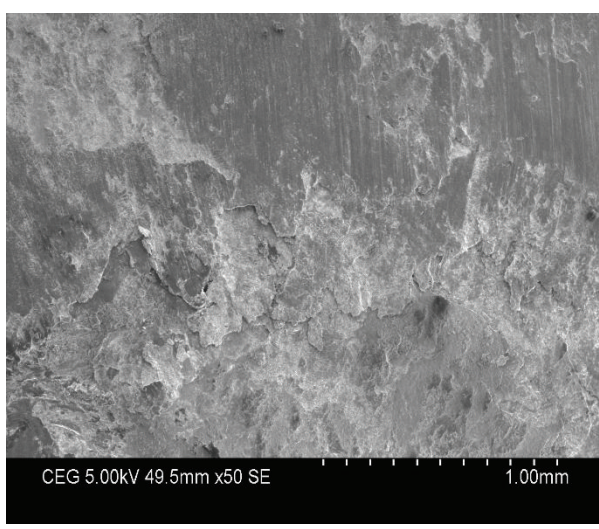

(e)

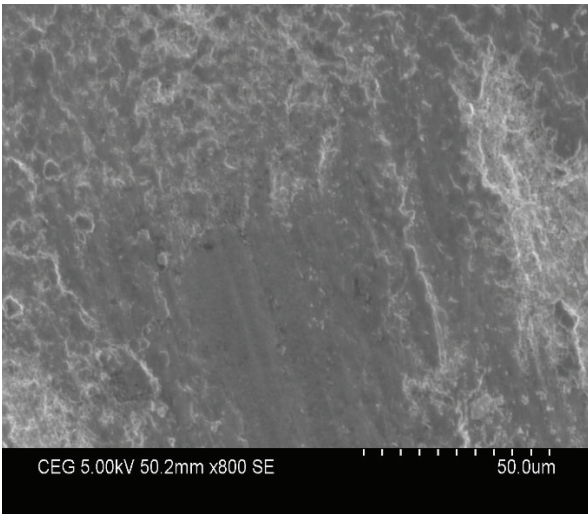

(b)

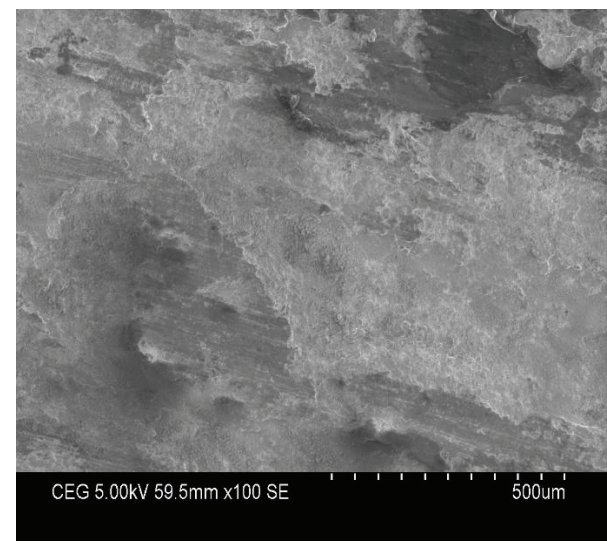

(d)

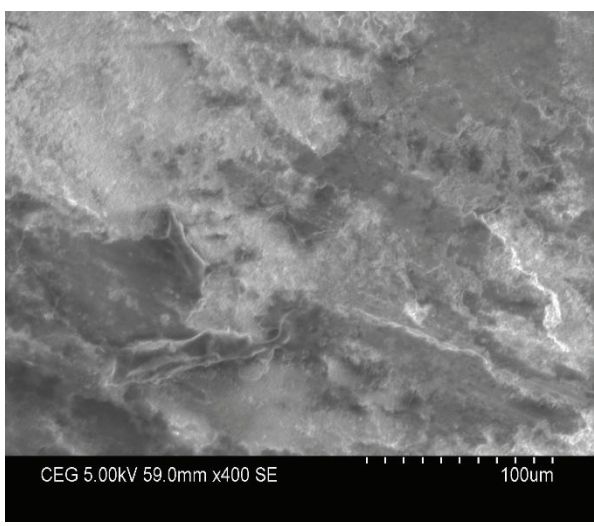

(f)

Figure 11: SEM micrographs of (a) $\mathrm{Al}$ at $0.1 \mathrm{~kg}$, (b) $\mathrm{Al}+1 \mathrm{wt} \%$ at $0.1 \mathrm{~kg}$, (c) $\mathrm{Al}$ at $0.2 \mathrm{~kg}$, (d) $\mathrm{Al}+1 \mathrm{wt} \%$ at $0.2 \mathrm{~kg}$, (e) $\mathrm{Al}$ at $0.3 \mathrm{~kg}$, and (f) $\mathrm{Al}+$ $1 \mathrm{wt} \%$ at $0.3 \mathrm{~kg}$.

the remaining sliding distance, the friction coefficient of the monolithic alloy and the $0.5 \mathrm{wt} \%, 1.0 \mathrm{wt} \%, 1.5 \mathrm{wt} \%$, and $2.0 \mathrm{wt} \%$ CNT composites remained almost constant at average values of $0.11,0.105,0.10,0.098$, and 0.095 , respectively.

3.5. Friction and Wear Mechanisms. SEM micrographs of worn surfaces after tests at different loads are presented in Figure 11. It can be seen that, at a load of $0.1 \mathrm{~kg}$, abrasion is dominant for the monolithic alloy and CNT composite leaving small wear marks as shown in Figures 11(a) and 11(b), respectively. Minor delamination can be found in monolithic alloy (cf. Figure 11(a)) whereas the composite did not show any delamination (cf. Figure 11(b)). This is due to greater hardness and strength imparted in the composite by the addition of CNTs. At a load of $0.2 \mathrm{~kg}$, considerable abrasion along with mild delamination can be seen for monolithic alloy in Figure 11(c). Significant delaminated flakes with crack initiation can be seen at several locations for the composite in Figure 11(d). Increasing the applied load to 


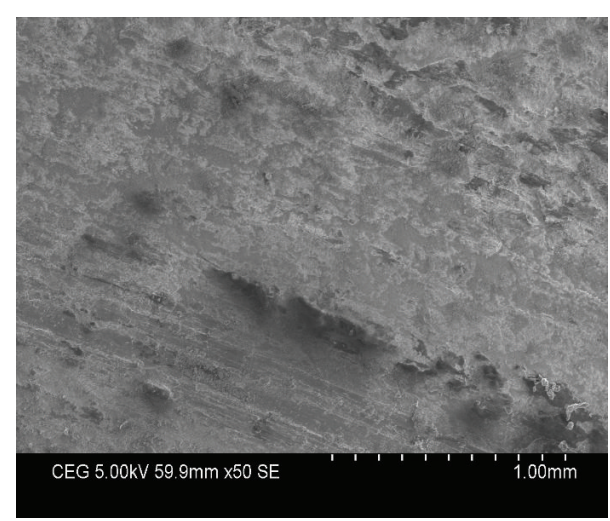

(a)

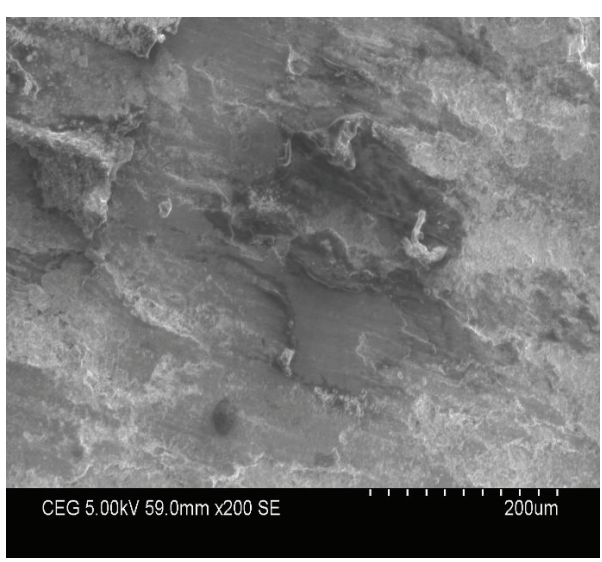

(c)

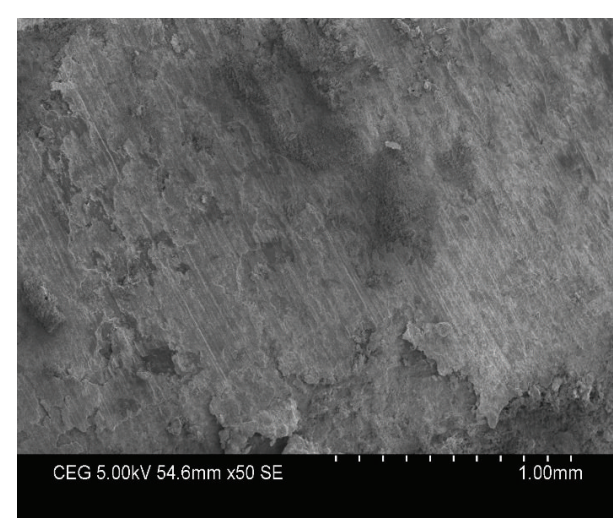

(b)

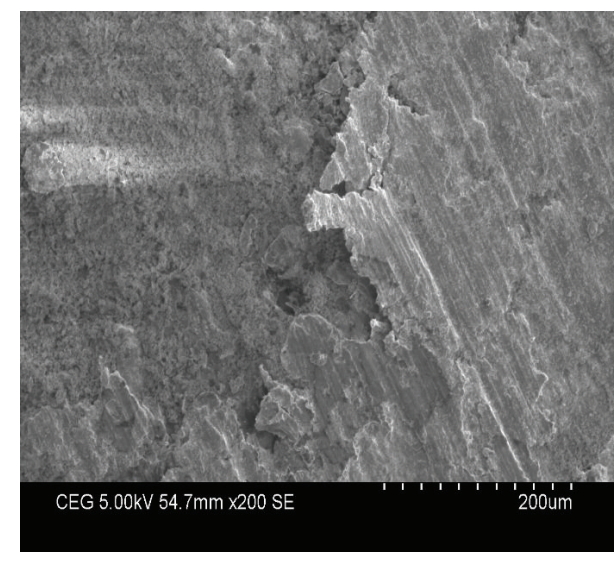

(d)

FIgURE 12: SEM micrograph at $0.5 \mathrm{~kg}$ of (a) and (c) $\mathrm{Al}$ and (b) and (d) $\mathrm{Al}+1 \mathrm{wt} \%$.

$0.3 \mathrm{~kg}$, the monolithic alloy displayed severe delamination with some possible breakage of adhesive junction as shown in Figure 11(e), while the composite showed severe subsurface fracturing and deep pits in Figure 11(f). It shows that cracks have initiated and propagated as a result of surface fatigue at higher loads during sliding leading to heavy delamination and hence high wear rate of the composite. The weak bonding between CNTs and Al particles in sintered samples could be another reason for crack initiation and propagation at higher loads.

Figures 12(a) and 12(b) show lower magnification SEM micrographs of worn surfaces at an applied load of $0.5 \mathrm{~kg}$ for the alloy and composite, respectively. The surface of the alloy is characterized by the formation of long and deep grooves. Such grooves could have been formed due to continuous abrasion of the specimen by the counterface. However, the surface of the composite is characterized by severe fracture and delamination, especially at the edges of the cylinder. This breaking of sharp edge during wear test at high loads may be attributed to weak bonding between CNTs and Al particles in the composite. Higher magnification SEM micrographs of worn surfaces clearly revealed the severe fracture and deep groove in the monolithic alloy and composite as can be seen in Figures 12(c) and 12(d), respectively. The deep grooves in the monolithic alloy (cf. Figure 12(c)) are typical of galling and material transfer caused by the roughened counterface as found by Casati and Vedani [3]. The roughness of the grooves in the composite (cf. Figure 12(d)) indicates the breakage of material due to the subsurface fracture. The results infer that the higher wear rate of composites under an applied load larger than $0.2 \mathrm{~kg}$ is correlated with the subsurface fracturing due to the increase in hardness and the reduction in fracture toughness.

\section{Conclusions}

The specimens were successfully sintered at suitable temperatures in ambient air and relevant tests also had been done for evaluating density, hardness, and tribological behaviour of carbon nanotubes reinforced aluminium metal matrix composites. Compared to other processing methods, this process has the potential to make large parts and does not require expensive equipment. The density of all samples was measured by Archimedes method and all had a theoretical density between $92.22 \%$ and $97.74 \%$. The microhardness was measured for aluminium and 0.5-2 wt\% CNT composites. The hardness increased with increasing fraction up to $1.5 \mathrm{wt} \%$ and then reduced at $2 \mathrm{wt} \%$. Wear and friction tests were conducted using "pin-on-disc" wear test apparatus. The micro/nanostructure was examined using high resolution 
field emission SEM to examine the distribution of CNTs in the matrix before and after pin-on-disc wear test. The SEM results were found to be correlated with wear rates. Wear rates and friction coefficient results were briefly discussed. The results showed that, under mild wear conditions, the CNTs reinforced $\mathrm{Al}$ composite displayed lower wear rate and friction coefficient compared to the monolithic $\mathrm{Al}$ alloy. However, for severe wear conditions, the composite displayed higher wear rate and friction coefficient compared to the monolithic alloy. Analysis of worn surfaces revealed that, at lower loads, abrasion was the dominant wear mechanism for both monolithic aluminium and composites. At higher loads, adhesion was found to be dominant for the monolithic alloy while subsurface fracturing and delamination were observed for the composite. Also, it was clarified that the friction and wear behaviour of $\mathrm{Al}$ composites is largely dependent on the applied load and there appears a critical load beyond which CNTs could have a negative impact on the wear resistance of the aluminium alloy.

It is envisaged that the densification and tribological properties of CNTs reinforced composites could be further improved by optimising the chemical pretreatment and dispersion of CNTs and to minimise the oxidation of the powders by carrying out the milling experiments to be carried out at room temperature under argon atmosphere. The densification can also be improved by secondary consolidation such as forging and rolling after cold compaction and sintering.

\section{Conflict of Interests}

The authors declare that there is no conflict of interests regarding the publication of this paper.

\section{Acknowledgments}

The authors wish to acknowledge the financial support from UGC (India) and British Council (UK) through UKIERIUGC Thematic Partnership (UKIERI-UGC-2012/13-032). Authors would like to thank the technicians of both Plymouth University and Anna University for their great support to conduct this research work.

\section{References}

[1] S. R. Bakshi, D. Lahiri, and A. Agarwal, "Carbon nanotube reinforced metal matrix composites-a review," International Materials Reviews, vol. 55, no. 1, pp. 41-64, 2010.

[2] N. Silvestre, "State-of-the-art review on carbon nanotube reinforced metal matrix composites," International Journal of Composite Materials, vol. 3, no. 6, pp. 28-44, 2013.

[3] R. Casati and M. Vedani, "Metal matrix composites reinforced by nano-particles-a review," Metals, vol. 4, no. 1, pp. 65-83, 2014.

[4] A. M. Al-Qutub, A. Khalil, N. Saheb, and A. S. Hakeem, "Wear and friction behavior of Al6061 alloy reinforced with carbon nanotubes," Wear, vol. 297, no. 1-2, pp. 752-761, 2013.

[5] C. R. Bradbury, J.-K. Gomon, L. Kollo, H. Kwon, and M. Leparoux, "Hardness of multi wall carbon nanotubes reinforced aluminium matrix composites," Journal of Alloys and Compounds, vol. 585, pp. 362-367, 2014.

[6] H. R. Le, M. P. F. Sutcliffe, and J. A. Williams, "Friction and material transfer in micro-scale sliding contact between aluminium alloy and steel," Tribology Letters, vol. 18, no. 1, pp. 99-104, 2005.

[7] I.-Y. Kim, J.-H. Lee, G.-S. Lee, S.-H. Baik, Y.-J. Kim, and Y.-Z. Lee, "Friction and wear characteristics of the carbon nanotube-aluminum composites with different manufacturing conditions," Wear, vol. 267, no. 1-4, pp. 593-598, 2009.

[8] S. Iijima, "Helical microtubules of graphitic carbon," Nature, vol. 354, no. 6348, pp. 56-58, 1991.

[9] Y. H. Lee, "The physical property and application of carbon nanotube," Sae Mulli, vol. 51, pp. 84-114, 2005.

[10] D. S. So, I. H. Lee, G. J. Bae, and W. J. Bak, "R\&D and market trend of carbon nanotube devices," Prospects of Industrial Chemistry, vol. 10, pp. 58-66, 2007.

[11] C. Qin, X. Shi, S. Q. Bai, L. D. Chen, and L. J. Wang, "High temperature electrical and thermal properties of the bulk carbon nanotube prepared by SPS," Materials Science and Engineering A, vol. 420, no. 1-2, pp. 208-211, 2006.

[12] T. Laha, A. Agarwal, T. McKechnie, and S. Seal, "Synthesis and characterization of plasma spray formed carbon nanotube reinforced aluminum composite," Materials Science \& Engineering A, vol. 381, no. 1-2, pp. 249-258, 2004.

[13] S. R. Bakshi, V. Singh, S. Seal, and A. Agarwal, "Aluminum composite reinforced with multiwalled carbon nanotubes from plasma spraying of spray dried powders," Surface and Coatings Technology, vol. 203, no. 10-11, pp. 1544-1554, 2009.

[14] T. Kuzumaki, K. Miyazawa, H. Ichinose, and K. Ito, "Processing of carbon nanotube reinforced aluminum composite," Journal of Materials Research, vol. 13, no. 9, pp. 2445-2449, 1998.

[15] R. George, K. T. Kashyap, R. Rahul, and S. Yamdagni, "Strengthening in carbon nanotube/aluminium (CNT/Al) composites," Scripta Materialia, vol. 53, no. 10, pp. 1159-1163, 2005.

[16] R. P. Bustamante, I. Estrada Guel, W. A. Flores, M. Yoshida, and P. J. Ferrira, "Novel Al-matrix nanocomposites reinforced with multi-walled carbon nanotubes," Journal of Alloys and Compounds, vol. 450, no. 1-2, pp. 323-326, 2008.

[17] A. M. K. Esawi, K. Morsi, A. Sayed, A. A. Gawad, and P. Borah, "Fabrication and properties of dispersed carbon nanotubealuminum composites," Materials Science \& Engineering A, vol. 508, no. 1-2, pp. 167-173, 2009.

[18] L. Wang, H. Choi, J.-M. Myoung, and W. Lee, "Mechanical alloying of multi-walled carbon nanotubes and aluminium powders for the preparation of carbon/metal composites," Carbon, vol. 47, no. 15, pp. 3427-3433, 2009.

[19] D. Poirier, R. Gauvin, and R. A. L. Drew, "Structural characterization of mechanically milled carbon nanotube/aluminummixture," Composites Part A: Applied Science and Manufacturing, vol. 40, pp. 1482-1489, 2009.

[20] R. P. Bustamante, G. D. Esparza, I. Guel, and M. Yoshida, "Microstructural and mechanical characterization of AlMWCNT composites produced by mechanical alloying," Materials Science \& Engineering A, vol. 502, pp. 159-163, 2009.

[21] A. M. K. Esawi, K. Morsi, A. Sayed, M. Taher, and S. Lanka, "The influence of carbon nanotube (CNT) morphology and diameter on the processing and properties of CNT-reinforced aluminium composites," Composites Part A: Applied Science and Manufacturing, vol. 42, no. 3, pp. 234-243, 2011. 
[22] J. Stein, B. Lenczowski, N. Fréty, and E. Anglaret, "Mechanical reinforcement of a high-performance aluminium alloy AA5083 with homogeneously dispersed multi-walled carbon nanotubes," Carbon, vol. 50, no. 6, pp. 2264-2272, 2012.

[23] Y. Wu, G.-Y. Kim, and A. M. Russell, "Effects of mechanical alloying on an Al6061-CNT composite fabricated by semi-solid powder processing," Materials Science and Engineering A, vol. 538, pp. 164-172, 2012.

[24] Y. Wu and G.-Y. Kim, "Carbon nanotube reinforced aluminum composite fabricated by semi-solid powder processing," Journal of Materials Processing Technology, vol. 211, no. 8, pp. 1341-1347, 2011.

[25] J. Wu, H. Zhang, Y. Zhang, and X. Wang, "Mechanical and thermal properties of carbon nanotube/aluminum composites consolidated by spark plasma sintering," Materials and Design, vol. 41, pp. 344-348, 2012.

[26] J.-Z. Liao, M.-J. Tan, and I. Sridhar, "Spark plasma sintered multi-wall carbon nanotube reinforced aluminum matrix composites," Materials and Design, vol. 31, no. 1, pp. S96-S100, 2010.

[27] Z. Y. Liu, B. L. Xiao, W. G. Wang, and Z. Y. Ma, "Singly dispersed carbon nanotube/aluminum composites fabricated by powder metallurgy combined with friction stir processing," Carbon, vol. 50, no. 5, pp. 1843-1852, 2012.

[28] H. Izadi and A. P. Gerlich, "Distribution and stability of carbon nanotubes during multi-pass friction stir processing of carbon nanotube/aluminum composites," Carbon, vol. 50, no. 12, pp. 4744-4749, 2012.

[29] L. Jiang, Z. Li, G. Fan, L. Cao, and D. Zhang, "The use of flake powder metallurgy to produce carbon nanotube (CNT)/ aluminum composites with a homogenous CNT distribution," Carbon, vol. 50, no. 5, pp. 1993-1998, 2012.

[30] H. Kwon, D. H. Park, J. F. Silvain, and A. Kawasaki, "Investigation on carbon nanotube reinforced aluminum matrix composite materials," Composites Science and Technology, vol. 70, no. 3, pp. 546-550, 2010.

[31] T. Noguchi, A. Magario, S. Fukazawa, S. Shimizu, J. Beppu, and M. Seki, "Carbon nanotube/aluminium composites with uniform dispersion," Materials Transactions, vol. 45, no. 2, pp. 602-604, 2004.

[32] H. J. Choi, S. M. Lee, and D. H. Bae, "Wear characteristic of aluminum-based composites containing multi-walled carbon nanotubes," Wear, vol. 270, no. 1-2, pp. 12-18, 2010.

[33] S.-M. Zhou, X.-B. Zhang, Z.-P. Ding, C.-Y. Min, G.-L. Xu, and W.-M. Zhu, "Fabrication and tribological properties of carbon nanotubes reinforced $\mathrm{Al}$ composites prepared by pressureless infiltration technique," Composites Part A: Applied Science and Manufacturing, vol. 38, no. 2, pp. 301-306, 2007.

[34] M. Zhu, Y. Gao, C. Y. Chung et al., "Improvement of the wear behaviour of $\mathrm{Al}-\mathrm{Pb}$ alloys by mechanical alloying," Wear, vol. 242, no. 1-2, pp. 47-53, 2000.

[35] C. Suryanarayana, "Synthesis of nanocomposites by mechanical alloying," Journal of Alloys and Compounds, vol. 509, no. 1, pp. S229-S234, 2011.

[36] S. C. Tjong, Carbon Nanotube Reinforced Composites. Metal and Ceramic Composites, Wiley-VCH, New York, NY, USA, 2009.

[37] S. R. Bakshi, V. Singh, K. Balani, D. G. McCartney, S. Seal, and A. Agarwal, "Carbon nanotube reinforced aluminum composite coating via cold spraying," Surface \& Coatings Technology, vol. 202, no. 21, pp. 5162-5169, 2008.

[38] S. Simões, F. Viana, M. A. Reis, and M. F. Vieira, "Influence of dispersion/mixture time on mechanical properties of Al-CNTs nanocomposites," Composite Structures, vol. 126, pp. 114-122, 2015. 

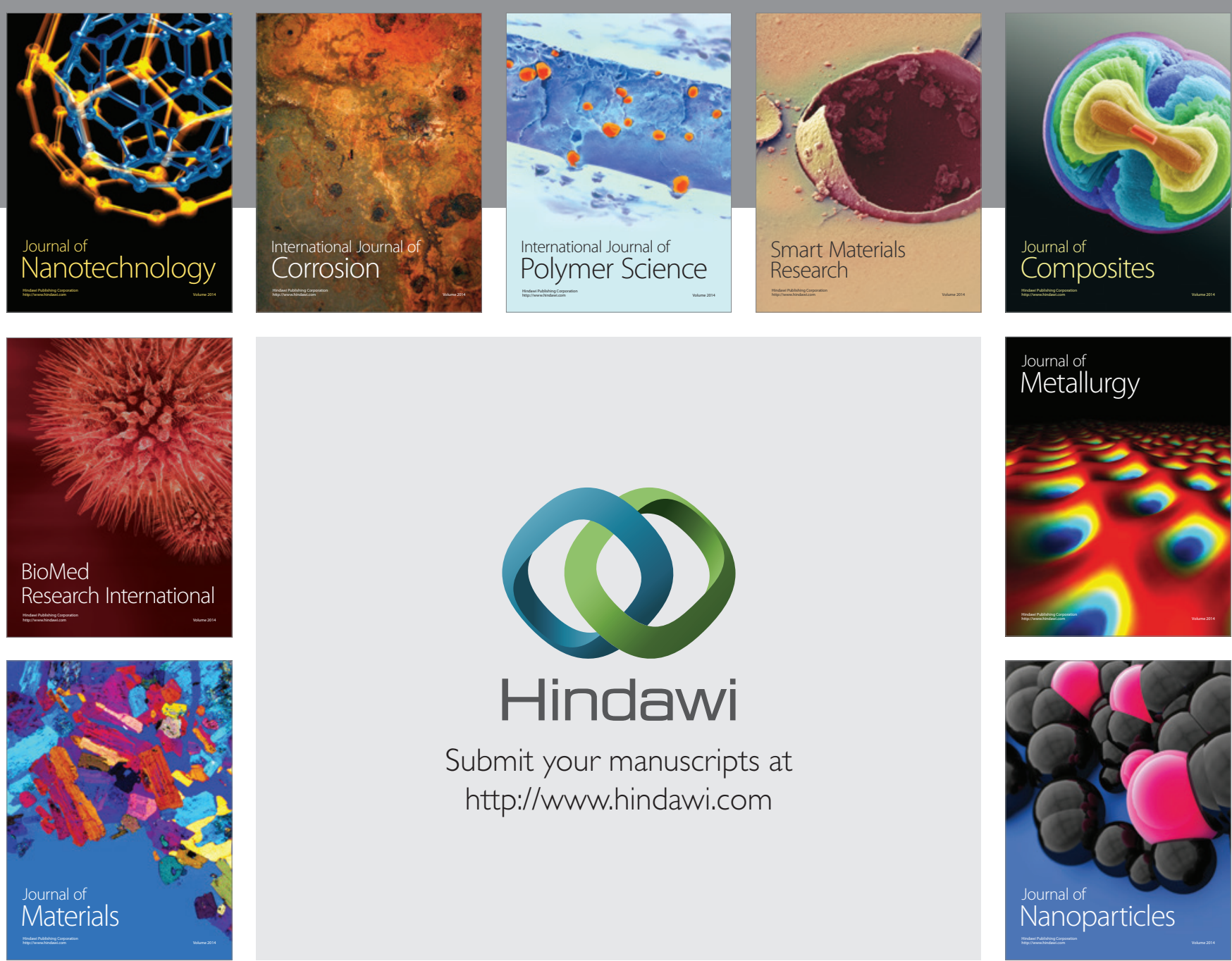

\section{Hindawi}

Submit your manuscripts at

http://www.hindawi.com

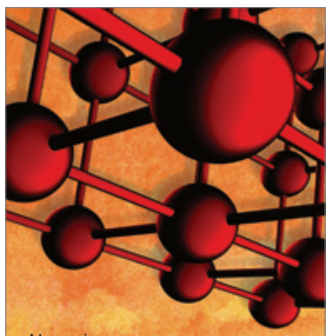

Materials Science and Engineering
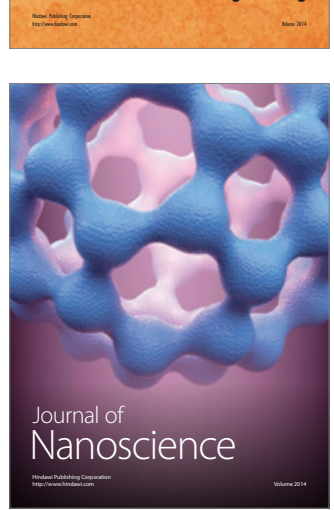
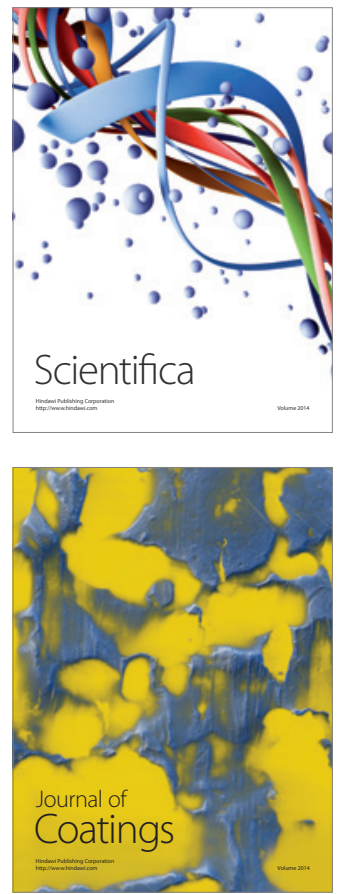
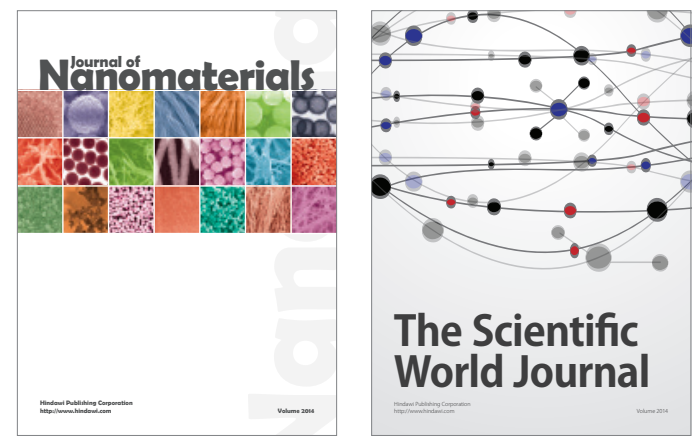

The Scientific World Journal
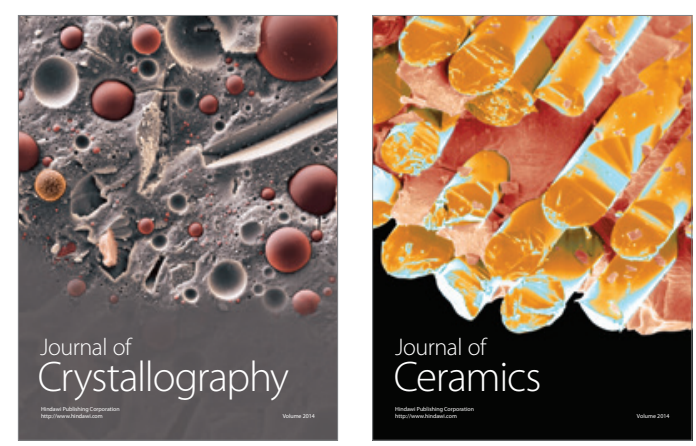
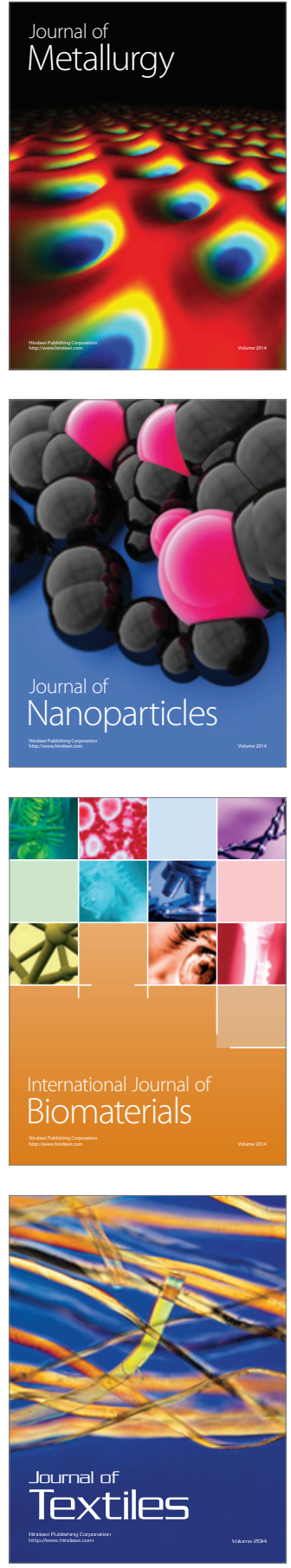